vs $<65$ yrs. Through W52, $66 \%$ of IV GLM pts and $62 \%$ of IFX pts discontinued the study. Discontinuation due to lack of efficacy was generally similar across age groups within treatment groups, although somewhat higher for IV GLM (29\%) vs IFX (19\%). For both treatments, AEs and discontinuations due to AE through W52 were more common in pts $\geq 65$ vs $<65$ yrs (Table 1 ). Consistent with general trends observed in elderly individuals, ${ }^{1}$ rates of serious AEs (SAEs) and serious infections increased with age for both IV GLM and IFX; however, increases were more notable in IFX- than IV GLM-treated pts $\geq 65 \mathrm{yrs}$. The incidence of serious infections was highest in pts $\geq 75 \mathrm{yrs}$ for both treatments, although small sample size may limit data interpretation. No increase in opportunistic infections, including Varicella, was observed in pts $\geq 65$ vs $<65 \mathrm{yrs}$. Infusion reactions were more common in pts $<65 \mathrm{yrs}$ in both treatment groups, and more prevalent in IFX- than IV GLM-treated pts within each age group through W52. Generally similar safety results were seen between W52 and W104 for each treatment group (data not shown). Both IV GLM and IFX in bionaïve pts showed improvement in CDAI scores across age groups, which was maintained over time (Figure 1).

Table 1. $\%$ of pts with $\geq 1 \mathrm{AE}$ through W52 DBL

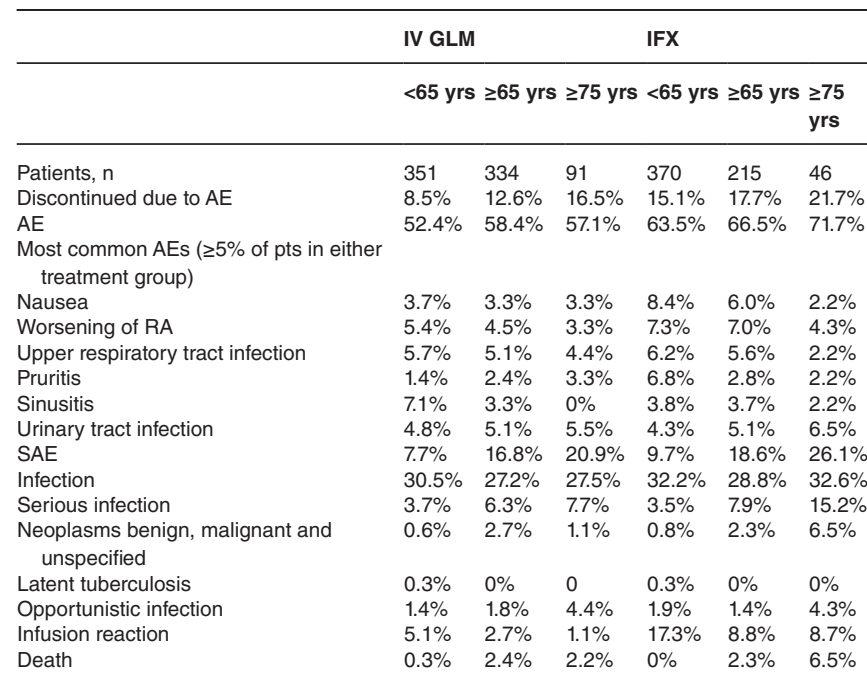

Figure. Mean (SD) change from baseline CDAl score at 6 months and 12 months (observed data) for bionaive population ${ }^{\mathrm{a}}$
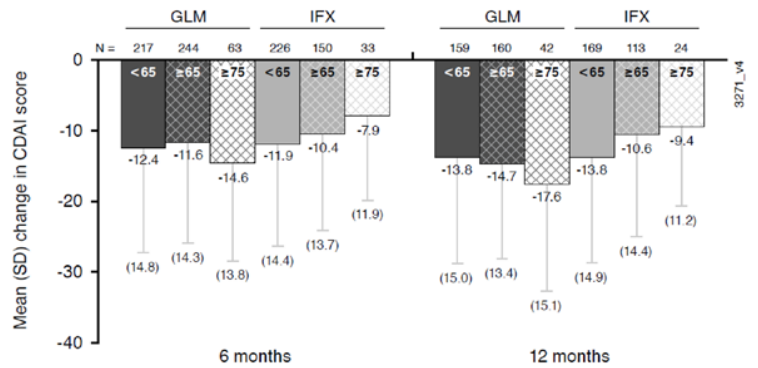

Conclusion: Elderly RA pts receiving IV GLM or IFX in this RWE study demonstrated similar safety and efficacy as reported in Phase 3 trials., ${ }^{2,3}$ The higher rates of $\mathrm{AEs}$, discontinuations due to $\mathrm{AE}$, and SAEs (mainly serious infections) observed in pts $\geq 65$ yrs are in line with increased safety events seen in elderly vs younger individuals in the general population. Rates of AEs, SAEs, and infusion reactions were higher for IFX vs IV GLM. Infusion reactions were more common in pts $<65$ vs $\geq 65$ yrs for both GLM and IFX, but more prevalent with IFX.

REFERENCES:

[1] Castle SC. Clin Infect Dis 2000;31:578-85.

[2] Lipsky PE, et al. N Engl J Med 2000;343:1594-602.

[3] Weinblatt ME, et al. Ann Rheum Dis 2013;72:381-9.

Disclosure of Interests: Joy Schechtman: None declared, Aaron Broadwell Speakers bureau: Amgen, AbbVie, Eli Lilly, Horizon, Janssen, Mallinckrodt, Novartis, Pfizer, Radius, Sanofi/Regeneron, and UCB, Consultant of: AbbVie,
Amgen, Aurinia, Celegene, Eli Lilly, Janssen, Novartis, Pfizer, and Sandoz, Shelly Kafka Shareholder of: Johnson \& Johnson, Employee of: Janssen Research \& Development, LLC, Shawn Black Shareholder of: Johnson \& Johnson, Employee of: Janssen Research \& Development, LLC, Stephen Xu Shareholder of: Johnson \& Johnson, Employee of: Janssen Research \& Development, LLC, Wayne Langholff Shareholder of: Johnson \& Johnson, Employee of: Janssen Research \& Development, LLC, Sergio Schwartzman Shareholder of: Amgen, Boston Scientific, Gilead, Medtronic, and Pfizer, Speakers bureau: AbbVie, Janssen, Eli Lily, Novartis, Pfizer, Regeneron, Sanofi, and UCB, Consultant of: AbbVie, Gilead, Eli Lilly, Janssen, Myriad, Novartis, Regeneron, Samsung, Sanofi, and UCB DOI: 10.1136/annrheumdis-2021-eular.165

\section{POS0591 SARILUMAB ATTENUATES DISEASE ACTIVITY IN SERONEGATIVE RA PATIENTS - PRELIMINARY DATA FROM A NON-INTERVENTIONAL STUDY IN REGULAR CARE IN GERMANY}

H. Burkhardt ${ }^{1}$, H. P. Tony ${ }^{2}$, P. M. Aries ${ }^{3}$, S. Zinke ${ }^{4}$, K. Krueger ${ }^{5}$, J. Ahlers ${ }^{6}$, R. Hecker ${ }^{6}$, I. Albrecht ${ }^{7}$, S. Kalus ${ }^{8}$, O. Bley ${ }^{9}$, P. Sternad ${ }^{10}$, A. D. Holst ${ }^{11}$, N. T. Baerlecken ${ }^{12}$, T. Klopsch ${ }^{13}$, M. Welcker ${ }^{10}$, E. Feist ${ }^{14} .{ }^{1}$ University Hospital Frankfurt, Division of Rheumatology, Frankfurt am Main, Germany; ${ }^{2}$ University Hospital Würzburg, Rheumatology/Clinical Immunology, Department of Internal Medicine II, Würzburg, Germany; ${ }^{3}$ Rheumatologie im Struenseehaus, Internal Medicine and Rheumatology, Hamburg, Germany; ${ }^{4}$ Medical Practice Dr. Med. Zinke, Internal Medicine and Rheumatology, Berlin, Germany; ${ }^{5}$ Praxiszentrum St. Bonifatius, Internal Medicine and Rheumatology, München, Germany;

${ }^{6}$ Sanofi-Aventis Deutschland GmbH, Rheumatology, Berlin, Germany;

${ }^{7}$ Sanofi-Aventis Deutschland GmbH, Future Indications, Berlin, Germany; ${ }^{8} \mathrm{GKM}$ Gesellschaft für Therapieforschung $\mathrm{mbH}$, Biostatistics, München, Germany; ${ }^{9}$ Sanofi-Aventis Deutschland GmbH, Clinical Study Unit, Berlin, Germany; ${ }^{10} \mathrm{MVZ}$ für Rheumatologie Dr. Martin Welcker, Internal Medicine and Rheumatology, Planegg, Germany; ${ }^{11}$ Private Practice Dr. Med. Holst, Internal Medicine and Rheumatology, Ludwigslust, Germany; ${ }^{12}$ Rheumatologie Köln Dr. Niklas Baerlecken / Dr. Thomas Karger, Internal Medicine and Rheumatology, Cologne, Germany; ${ }^{13}$ Private Practice Dr. Med. Klopsch, Internal Medicine and Rheumatology, Neubrandenburg, Germany; ${ }^{14} \mathrm{HELIOS}$ Clinic VogelsangGommern, Department of Rheumatology and Immunology, Gommern, Germany

Background: Although seronegative RA patients often present with substantial disease burden [1], patients are underrepresented in research cohorts or clinical trials. Consequently, less knowledge about this subgroup has been accumulated. Objectives: To describe outcome of seronegative vs. seropositive RA patients treated with sarilumab in regular care in Germany.

Methods: The prospective, observational, 24-month single-arm PROSARA study (SARILL08661) is currently running in Germany at 96 sites, aiming to enroll up to 750 RA patients treated with sarilumab. RA patients are prospectively selected at physician's discretion according to label, and medical history is documented before treatment. This interim analysis included patients with data available up to 24 months. Here we focus on sustained treatment response after 6 and 12 months, respectively. Patients were stratified according to serostatus (RF- AND ACPA- as seronegative or RF+ AND/OR ACPA+ as seropositive). All analyses are descriptive only.

Results: To date 473 patients were included in the study, of which $22.2 \%$ $(n=105)$ were seronegative and $59.0 \%(n=279)$ were seropositive (Table 1). For 89 patients $(18.8 \%)$ serostatus was not specified.

The mean time since diagnosis of RA was shorter in seronegative than in seropositive patients $(7.9 \pm 7.6$ years vs. $11.5 \pm 9.9$ years) (Table 1$)$.

At baseline, CDAl score was $27.7 \pm 14.7(n=104)$ and $23.0 \pm 12.9(n=272)$ in seronegative and seropositive patients, respectively. After 12 months of sarilumab treatment, CDAl improved to $15.6 \pm 12.3(n=38)$ and 9.1 $\pm 8.7(n=101)$ in seronegative and seropositive, respectively, for patients with post-baseline data available. At that time, remission/low disease activity according to CDAI was reached by $5.3 \%(n=2 / 38) / 39.5 \%(n=15 / 38)$ of seronegative patients, respectively and by $26.7 \%(n=27 / 101) / 68.3 \%(n=69 / 101)$ of seropositive patients, respectively (Fig. 1A, B).

Physical function, assessed by HAQ-DI, was slightly more impaired in seronegative patients $(1.4 \pm 0.7)$ than in seropositive patients $(1.2 \pm 0.7)$ at baseline. HAQ-D improved over 12 months to $0.9 \pm 0.7$ in seropositive patients $(n=90)$ but showed no change in seronegative patients $(1.4 \pm 0.7 ; n=37)$ (Fig. 1C).

Safety was consistent with the anticipated profile of IL-6-R-inhibition and no new safety signals occurred. Adverse events and serious adverse events were described in $61.7 \%$ and $12.8 \%$ of seronegative patients, respectively and in $55.2 \%$ and $13.7 \%$ of seropositive patients, respectively. 
Table 1. Baseline data regarding patient characteristics, prior treatment and disease activity

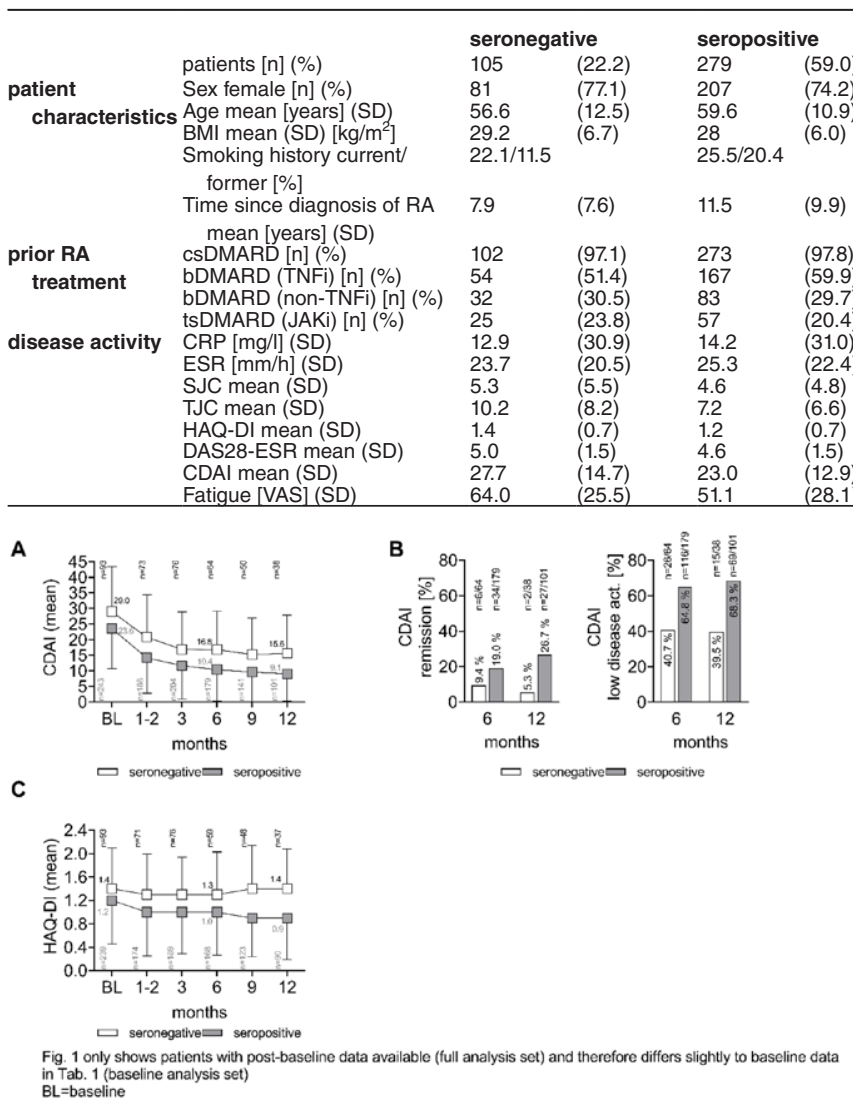

Figure 1. $C D A I(A, B)$ and $H A Q-D I(C)$ outcomes in seronegative and seropositive patients

Conclusion: Sarilumab treatment ameliorated CDAI in both seronegative $(\triangle \mathrm{CDAl}-17.0 \pm 16.5)$ and seropositive ( $\triangle \mathrm{CDAl}-15.4 \pm 14.3)$ patients to the same extent over the course of 12 months, with a higher remission rate in seropositive patients. Functional capacity improved meaningfully in the seropositive cohort but had no significant impact in seronegative patients. The safety profile was consistent with data reported from controlled clinical trials.

REFERENCES:

[1] Choi S-T et al. (2018) PLoS ONE 13(4): e0195550.

Acknowledgements: We thank Cornelia Kühne (Haldensleben) for substantial contribution to patient recruitment in PROSARA.

Disclosure of Interests: Harald Burkhardt Speakers bureau: Sanofi, Pfizer, Roche, Abb- vie, Boehringer Ingelheim, UCB, Eli Lilly, Chugai, Bristol Myer Scribb, Janssen, and Novartis, Consultant of: Sanofi, Pfizer, Roche, Abbvie, Boehringer Ingelheim, UCB, Eli Lilly, Chugai, Bristol Myer Scripps, Janssen, and Novartis, Grant/research support from: Pfizer, Roche, Abbvie, Hans-Peter Tony Consultant of:AbbVie, Astra-Zeneca, BMS, Chugai, Janssen, Lilly, MSD, Novartis, Pfizer, Roche, Sanofi, Peer-Malte Aries Speakers bureau: Abbvie, Biogen, Berlin Chemie, Celgene, GSK, Hexal, Mylan, Novartis, Pfizer, UCB, Consultant of: Abbvie, Celgene, Hexal, Janssen, Medac, Novartis, Pfizer, Sanofi, UCB, Silke Zinke: None declared, Klaus Krueger Speakers bureau: Sanofi, Jonas Ahlers Employee of: Sanofi, Rolf Hecker Employee of: Sanofi, Inka Albrecht Employee of: Sanofi, Stefanie Kalus Consultant of: Sanofi, Oliver Bley Employee of: Sanofi, Patrizia Sternad: None declared, Ann-Dörthe Holst: None declared, Niklas Thomas Baerlecken: None declared, Thilo Klopsch: None declared, Martin Welcker Speakers bureau: Abbvie, Aescu, Amgen, Biogen, Berlin Chemie, Celgene, GSK, Hexal, Mylan, Novartis, Pfizer, UCB, Consultant of: Abbvie, Actelion, Aescu, Amgen, Cel- gene, Hexal, Janssen, Medac, Novartis, Pfizer, Sanofi, UCB, Grant/research support from: Abbvie, Novartis, UCB, Hexal, BMS, Lilly, Roche, Celgene, Sanofi, Eugen Feist Speakers bureau: Novartis, Roche, Sobi, Lilly, Pfizer, Abbvie, BMS, MSD, Sanofi, Consultant of: Novartis, Roche, Sobi, Lilly, Pfizer, Abbvie, BMS, MSD, Sanofi

DOI: 10.1136/annrheumdis-2021-eular.232

\begin{tabular}{|l|l}
\hline POS0592 & BIOSIMILAR INFLIXIMAB THERAPY IN RHEUMATOID \\
ARTHRITIS, ANKYLOSING SPONDYLITIS AND PSORIATIC \\
ARTHRITIS: A LONG-TERM FOLLOW-UP STUDY ON \\
INFLIXIMAB-NAÏVE PATIENTS AND PATIENTS SWITCHED \\
FROM THE ORIGINATORTOTHE BIOSIMILAR CT-P13
\end{tabular}

B. Fautrel ${ }^{1}$, M. Assing ${ }^{2}$, N. Mammar ${ }^{2}$, H. Marotte ${ }^{3} .{ }^{1}$ Sorbonne University Assistance Publique-Hopitaux de Paris, Pitié-Salpêtrière Hospital, Paris, France; ${ }^{2}$ PFIZER, Inflammation \& Immunology, Paris, France; ${ }^{3}$ SAINBIOSE
INSERM U1059 and Rheumatology department, University of Lyon and University Hospital of Saint-Etienne, Saint-Etienne, France

Objectives: The ReFLECT study was carried out to investigate real life use of CT-P13, the first monoclonal antibody biosimilar to infliximab originator.

Methods: ReFLECT is a multicentre, prospective, observational study conducted in France to determine the characteristics of patients (pts) receiving CT-P13, its effectiveness and safety in a real-life setting. Eligible were both pts who had been switched from infliximab originator (IFX $)$ and infliximab-naïve pts started on CT-P13 (IFX) Intermediate results in pts with rheumatic diseases using descriptive statistical analyses from inclusion to a 24-month-follow-up period are described here.

Results: Among the 1370 adult pts included between October 2016 and April 2019, data were analysed for 142 pts with rheumatoid arthritis (RA; $23.9 \%$ males mean age: $61.5 \pm 10.9$ years; 80 IFX $/ 61$ IFX $)$, 411 with ankylosing spondylitis (AS; $58.9 \%$ males; $48.1 \pm 13.1$ years; $228 \mathrm{IFX}_{\mathrm{N}} / 179 \mathrm{IFX}$ ), and 96 with psoriatic arthritis (PsA; $41.7 \%$ males; $53.4 \pm 14.1$ years; 55 IFX $/ 40$ IFX $_{\mathrm{S}}$ ) after a median of between 8.7 and 12.9 years since diagnosis. At inclusion, $66.9 \%, 24.3 \%$ and $50 \%$ had one concomitant treatment, mainly methotrexate. At the time of the first administration of CT-P13, disease had been active in $94.2 \%, 76.6 \%$ and $83.3 \%$ of the IFX pts compared with $45.3 \%, 24.0 \%$ and $32.0 \%$ of the IFX pts. After 24 months of follow-up, both CRP levels and disease activity remained stable compared to baseline in the IFX ${ }_{S}$ pts: median $\triangle$ CRP $\mathrm{RA}_{\mathrm{S}}=1, \Delta \mathrm{CRP} / \mathrm{AS}_{\mathrm{S}}=0, \Delta \mathrm{CRP} /$ $\mathrm{PSA}_{\mathrm{S}}=0$ and median $\triangle \mathrm{DAS} 28 / \mathrm{RA}_{\mathrm{S}}=0, \Delta \mathrm{BASDAl} \mathrm{AS}_{\mathrm{S}}=0, \Delta \mathrm{DAS} 8 / \mathrm{PsA}_{\mathrm{S}}=1$. As expected, improvement was observed in the IFX $\mathrm{N}_{\mathrm{N}}$ pts: median $\triangle \mathrm{CRP} / \mathrm{RA} \mathrm{A}_{\mathrm{N}}=-2$

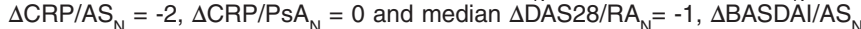
$=-2, \Delta \mathrm{DAS}_{28} / \mathrm{PsA}_{\mathrm{N}}=-1$. In naïve pts, CT-P13 brought both CRP and disease activity down to levels comparable to those seen in patients switched from the IFX originator: median [Q1;Q3] CRP/RA $A_{N}=5$ [2;9] vs CRP/RA $=5$ [2;8]; CRP/ $\mathrm{AS}_{\mathrm{N}}=3[2 ; 9]$ vs CRP/AS $=3[2 ; 5] ; \mathrm{CRP} / \mathrm{PsA}_{\mathrm{N}}=2[1 ; 4]$ vs $\mathrm{CRP} / \mathrm{Ps} \mathrm{A}_{\mathrm{S}}=2[1 ; 3]$ and median [Q1;Q3] DAS28/RA $=3$ [3;4] vs DAS28/RA $=2$ [2;3]; BASDAl/AS $=3[1 ; 4]$ vs BASDAl/AS $=2[1 ; 3] ; \mathrm{DAS}_{\mathrm{S}}=28 / \mathrm{PsA}_{\mathrm{N}}=3[2 ; 3]$ vs DAS28/PsA $=3$ [2;3], (Figure 1). At 24 months, $62.7 \%, 74.9 \%$ and $75.0 \%$ remained on treatment with CT-P13 in RA, AS and PsA pts respectively. The reasons for treatment withdrawing and safety results are reported in Table 1.

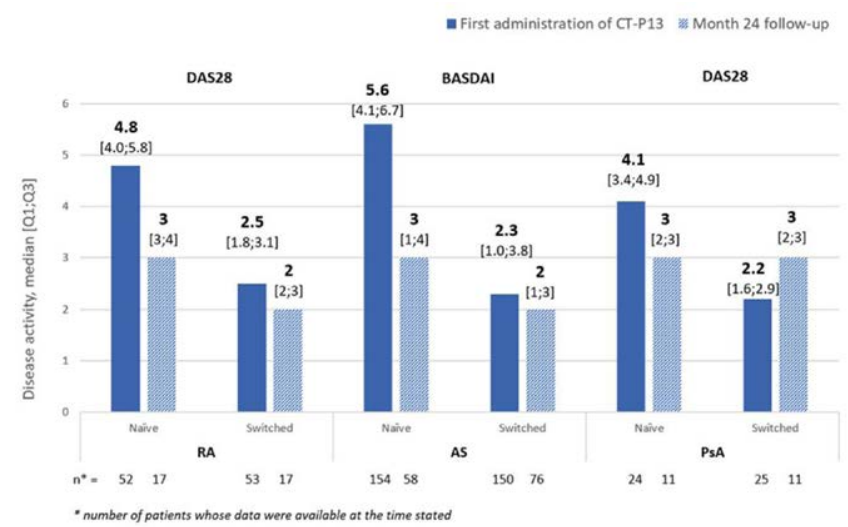

Figure 1. Disease activity at the time of first administration of CT-P13 and after 24 months

Table 1. Reasons for treatment withdrawing and safety results

Reasons for treatment withdrawing

IFX pts, $n$ (\%) $\quad$ RA $_{N}, 37$ RAs, 15 AS $_{N}, 64$ ASs, 38 PsA, 11 PsAs, 12

\begin{tabular}{|c|c|c|c|c|c|c|}
\hline Missing & 1 & 0 & 0 & 0 & 0 & 1 \\
\hline Remission & 0 & $2(13.3)$ & $2(3.1)$ & 0 & 0 & 0 \\
\hline Therapeutic failure * & $25(69.4)$ & $8(53.3)$ & $41(64.1)$ & $23(60.5)$ & $5(45.5)$ & $6(54.5)$ \\
\hline Intolerance & $5(13.9)$ & $1(6.7)$ & $5(7.8)$ & $2(5.3)$ & $1(9.1)$ & $1(9.1)$ \\
\hline Other & $6(16.7)$ & $4(26.7)$ & $16(25.0)$ & $13(34.2)$ & $5(45.5)$ & $4(36.4)$ \\
\hline Safety data, n (\%) & RA, 142 & & AS, 411 & & PsA, 96 & \\
\hline Pts with $\geq 1$ adverse event (AE) & 67 (47.2) & & $222(54.0)$ & & $48(50.0)$ & \\
\hline Pts with $\geq 1 \mathrm{AE}$ related to $\mathrm{CT}-\mathrm{P} 13$ & $33(23.2)$ & & $84(20.4)$ & & 19 (19.8) & \\
\hline Pts with $\geq 1$ serious $A E$ & 19 (13.4) & & $42(10.2)$ & & $9(9.4)$ & \\
\hline $\begin{array}{l}\text { Pts with } \geq 1 \text { allergic infusion } \\
\text { reaction }\end{array}$ & $4(2.8)$ & & $11(2.7)$ & & $1(1.0)$ & \\
\hline Pts with $\geq 1$ infection ${ }^{\ddagger}$ & $10(7.0)$ & & $18(4.4)$ & & $3(3.1)$ & \\
\hline
\end{tabular}

${ }^{*}$ Encompassing primary failure in IFX $X_{N}$ pts and loss of efficacy in IFX $X_{N}$ and IFX ${ }_{S}$ pts $†$ Including acute and delayed hypersensitivity reactionsł Including severe infections, tuberculosis, opportunistic infections, hepatitis

Conclusion: Year 2 follow-up data indicate that CT-P13 effectively induced improvement in disease activity in pts with RA, AS and PSA receiving infliximab for the first time and maintained stable disease activity in pts switched from 